\title{
DÍA ACIAGO: 6:30 DE LA TARDE
}

Armando Pereira*

...y aqui he aprendido que la relación más humana entre dos personas es el silencio.

Bohumil Hrabal

-No sé si deba hacerlo. Ahora usted viene aquí y me pide que se lo cuente todo. ¿Por qué tengo que contarlo todo? Él me pidió que no lo hiciera, que era un secreto entre los dos, que nos jugábamos la vida si lo contaba. Es verdad que él ya está muerto y a mí la vida sin él ya no me importa tanto, me da igual. Sin él vivo las horas y los días vacíos, como una autómata: de la cocina a la sala, de la sala al baño, del baño a la recámara. A veces pongo la televisión, pero enseguida me aburre. Apago las luces, aunque tampoco así puedo dormir. ¿Qué quiere que le diga?

No ha corrido las cortinas y la habitación permanece en penumbras. Sólo una luz tenue, proveniente de una lámpara sobre la mesita lateral junto al sofá, ilumina la estancia. Me cuesta distinguir los objetos que nos rodean. Pero mi primera sensación es de estrechez, de austeridad, como su cuerpo, como ella misma.

-Usted vivió una vida con él que nadie conoce, usted debe saber algunas cosas que nadie sabe. Yo estoy escribiendo un libro sobre él y usted puede ayudarme.

- ¿Va a contar la verdad?

-Voy a inventarla, si usted me ayuda.

* Departamento Académico de Estudios Generales, ITAM. 
-¿Por qué voy a ayudarlo a inventar la verdad? ¿Por qué no la cuenta nada más y se deja de historias?

-Porque no creo que la verdad esté en ninguna parte. Es sólo un resultado ilusorio de ciertas conjeturas.

$-i Y$ quiere que yo contribuya a esa ilusión?

-Quiero que me lo cuente todo, después yo me haré cargo del resto.

-Venía aquí algunas tardes, entre seis y siete, sobre todo los martes y los jueves. A veces más tarde, ya entrada la noche, pero entonces sólo se quedaba un par de horas. Tenía una familia, una mujer y unos hijos, y se debía a ellos. Yo lo entendía, lo entendí siempre. Pero cuando venía temprano se tiraba en ese sillón, donde ahora está usted sentado, se aflojaba el nudo de la corbata, me pedía que le sirviera un whisky y empezaba a hablar, a contármelo todo. Nunca bebía más de dos o tres whiskies; creo que sólo intentaba relajarse. A veces se quedaba en silencio, con la vista perdida en la ventana, sin pronunciar palabra en toda la tarde. Nunca supe qué pensaba en esos momentos. Yo no me atrevía a hablar, a preguntarle nada. Me limitaba a mirarlo y a compartir callada su silencio. Sabía que ese silencio no era un silencio tranquilo, que estaba cargado de angustia, de ansiedad, de incertidumbre, pero igual compartía todo eso con él hasta que de pronto empezaba a hablar o se ponía de pie y se iba sin decir palabra.

El trabajo de periodista es muy duro. Usted debe saberlo, porque es periodista, según me dijo. Sobre todo cuando el periodista se ocupa de la política. ¿Por qué los hombres quieren saberlo todo, averiguarlo todo? ¿Por qué se meten en tantos líos? Desde hacía meses, él sabía que alguien le pisaba los talones. Nunca supo exactamente quién era, si la mafia, la ultraderecha, los norteamericanos o los propios políticos mexicanos. Yo le pedí que se callara, que escribiera sobre cualquier otra cosa, deportes, espectáculos, lo que fuera. Algo que nos permitiera vivir tranquilos, a él, a su familia y a mí, a mí con él, por supuesto. Y ahora que él ya murió lo tengo a usted frente a mí, preguntándome, 
pidiéndome que se lo cuente todo, decidido a no dejarme vivir tranquila, con mis recuerdos, que debían ser sólo míos.

Tiene las manos entrelazadas sobre una de sus piernas. Un poco rugosas, con las manchas oscuras de la edad. Sesenta y ocho, setenta años tal vez. Los ojos claros, apagados. Un rostro enjuto, inexpresivo, con arrugas en las comisuras de los ojos y los labios.

-Sólo quiero reconstruir su muerte, las razones de su muerte.

- ¿Y qué quiere que yo le diga? Las razones de su muerte..., como si yo las supiera. ¿Por qué muere un periodista? Por decir la verdad, por decir una verdad que otros no quieren que se sepa.

-¿Quiénes eran esos otros?

-No lo sé, pero sólo tiene que leer sus artículos en la prensa, sus libros. Manuel criticó a algunos sectores que hacían la política en esa época: la CIA, que no sólo intervenía en la política mexicana, sino que, desde México, actuaba en toda Centroamérica; los vínculos de la CIA con el narcotráfico; los grupos de ultraderecha, los famosos Tecos en Guadalajara; en fin, las altas esferas de la política en el país, que tenían vínculos con todos. No sé ahora, pero entonces todo era demasiado turbio, demasiado sucio, y él quería limpiarlo un poco. Sentía que era su deber, el deber de un periodista frente a sus lectores, mostrar a la gente lo que los políticos y otras fuerzas oscuras se empeñaban en ocultarle.

Él decía que tenía amigos, confiaba en ellos, tal vez por eso lograba vencer el miedo y seguir intentando esclarecer las cosas. Pero, por lo que dijeron las noticias después de su asesinato, fueron precisamente esos amigos los que lo traicionaron.

-¿José Antonio Zorrilla?

-No lo sé. Yo creo que Zorrilla fue el chivo expiatorio, al que culparon para que las cosas no llegaran más arriba, como siempre. Piénselo, ¿por qué si Zorrilla estaba bajo sospecha lo dejaron salir rumbo a España y vivir allá tanto tiempo?

Mientras habla, en su rostro no hay un solo gesto que pueda denunciar una emoción. Ha desenlazado las manos y las mueve sin 
relación alguna con sus palabras, como si su cuerpo y su voz estuvieran escindidos.

-Empecemos por partes. ¿Cuándo fue la última vez que usted lo vio?

-El jueves antes de su muerte. Llegó cansado, había tenido un día muy difícil. Nada más entrar por la puerta, se aflojó la corbata y se tiró en ese sofá donde está usted sentado ahora.

-¿De qué hablaron esa tarde?

-Estaba preocupado. Sabía que le seguían los pasos, que algo se fraguaba en torno a él, seguramente para silenciarlo. En ese entonces trabajaba en una investigación acerca del narcotráfico, en el que algunos funcionarios de alto nivel parecían estar involucrados. ¿Sabe qué me dijo esa noche? "A mí tendrán que matarme por la espalda, porque si me atacan de frente me llevaré a varios." Y así fue: lo mataron por la espalda.

-¿Le habló de José Antonio Zorrilla esa noche?

-Zorrilla era su amigo, uno de sus amigos. Unos días antes del atentado, le había regalado un chaleco antibalas y una pistola. ¿Usted cree que si Zorrilla tenía pensado matarlo le habría dado los medios de defenderse, de librarse del crimen? Por eso yo tengo mis dudas en todo esto, y sé que me voy a morir con ellas.

- Creo que además de dudas, tiene algunas certezas que no quiere contarme. Usted fue su amante, debe saber mucho más.

-No fui su amante; fui su confidente, que no es lo mismo. El no podía hablar con su esposa de ciertas cosas, por seguridad, para protegerla, a ella y a sus hijos, y las hablaba conmigo. Sólo fui su amiga, aunque a usted le parezca raro. Fuimos amigos desde la adolescencia, tal vez sólo entonces hubo algo entre nosotros. La mañana de su muerte me llamó por teléfono, me dijo que tal vez esa tarde pasaría a verme, pero nunca volvió. Yo todavía sigo esperándolo. Lo demás ya usted lo sabe.

-Quiero oír su versión.

-Sólo sé lo que dijeron los periódicos. 
30 de mayo de 1984. Día nublado con amago de lluvia, día aciago. Número 58 de la Avenida Insurgentes Sur, entre la glorieta del Metro y Paseo de la Reforma, exactamente enfrente de la Zona Rosa. 6:30 de la tarde: hora de salida de las oficinas, hora de entrada a los bares y restaurantes: bullicio en la calle, jolgorio, ajetreo. Después de las últimas llamadas telefónicas a amigos y familiares, Manuel Buendía se abotona su traje gris y se ajusta su gabardina azul. No cuenta con la compañía de Luis Soto, su secretario, que iba a pasar esa tarde con su esposa a punto de dar a luz a su primogénito. En su lugar, lo acompaña uno de sus ayudantes, un joven de diecisiete años, Juan Manuel Bautista. Salen juntos del edificio. El joven se adelanta a pedir el automóvil de Buendía en el estacionamiento, mientras el periodista espera en la puerta de salida de los coches. De pronto, desde uno de los postes de luz cercano, un hombre delgado, de mediana estatura, cejas pobladas, bigote espeso y con gesto decidido, se dirige hacia él con un revólver en la mano derecha. A escaso medio metro de la espalda del periodista, el victimario jala el gatillo y la bala entra perforando el hígado y el pulmón de la víctima. Buendía gira el cuerpo hasta casi encarar a su asesino. No tiene tiempo de sacar la pistola que le había regalado su amigo Zorrilla, tampoco lleva puesto el chaleco antibalas que lo hubiera librado de la muerte, tres tiros más le perforan el tórax y su pesado cuerpo cae sin vida sobre el asfalto. El asesino, con pantalón de mezclilla, chamarra negra de cuero, una gorra de beisbolista que le cubre hasta la mitad de la frente y zapatos tenis, corre, con la pistola todavía en la mano y ante una multitud paralizada por el miedo, hasta una motocicleta Honda que, encendida, lo espera en la calle Havre. Juan Manuel Bautista, empuñando la pistola de Buendía, corre detrás del homicida. Dos o tres hombres más, presentes en la escena del crimen, corren con él para apoyarlo. El humo de la motocicleta oculta el rastro de los victimarios.

-Después de eso - usted ya lo sabe o se lo imaginará-, vinieron las investigaciones. La procuradora Victoria Adato comenzó descartando las motivaciones políticas, como si en un caso como en el de Manuel los asuntos políticos pudieran descartarse tan fácilmente. Parecía actuar 
bajo consigna, como si le hubieran dicho: "saca el crimen de la esfera política, deslígalo de nosotros". Y así lo hizo: dirigió la investigación a cuestiones personales, pasionales para ser más específica. Y es que es más fácil y menos comprometedor investigar razones personales, sobre todo cuando las razones políticas son tan evidentes.

Por supuesto, me cayeron encima día y noche, me interrogaron, me vigilaron. La propia esposa de Manuel me llamó un día por teléfono y desayunamos juntas. Quería saber todo de mi relación con él. Yo no quería contárselo - hay cosas que una debe guardar para sí misma-, pero se lo conté de punta a cabo. Sabía por lo que ella estaba pasando que, sin duda, era bastante peor que lo mío. Y terminamos como amigas, eso puedo decírselo sin temor a equivocarme. Nunca volvimos a hablarnos, pero terminamos como amigas.

Fue un infierno. Duró meses, años incluso. Pero fue algo que purgué gustosa por Manuel. ¿Sabe usted qué sabe una mujer cuando se mete con alguien como Manuel? Que tendrá que pagar un precio. Y yo lo pagué gustosa. ¿Sabe por qué? No porque fuera su amante, como usted cree, sino porque fue un hombre limpio, demasiado limpio, y estaba solo, demasiado solo. Ni siquiera su mujer podía acompañarlo allí, en esas altas esferas del miedo, que no logran, sin embargo, acallar a una conciencia.

También su voz es plana. No modula las palabras. No hay cambio de tono de una frase a otra. Como si estuviera muerta, como si me hablara desde la muerte.

-Pero no fui la única que sufrió el asedio de judiciales y policías. En la medida en que algunos periodistas no se tragaron los 'motivos personales' y siguieron exigiendo en la prensa que se agarrara al toro por los cuernos, también a ellos se les fueron encima. Fue el caso de Rogelio Hernández, entre muchos otros. No sólo lo amenazaron a él, sino a toda su familia, hasta que tuvo que dejar de escribir sobre Buendía en Excelsior. El propio presidente Miguel de la Madrid borró de pronto de su agenda el tema Buendía y se negó a responder preguntas sobre el asunto. ¿Se acuerda del lío ese que se armó con un periodista 
español? En su entrevista con el presidente, le censuraron todas las preguntas que tenían que ver con el caso Buendía.

¿Sabe qué he pensado desde entonces? Que acallar a un periodista, censurarlo, ya no digamos matarlo o dejar impune su muerte, es amordazar a todo un pueblo, es el acto más dictatorial, más despótico, que puede existir, porque el periodista es la mirada y la voz de la gente que no tiene voz. Censurarlo, matarlo, es dejar mudos a millones de hombres y mujeres que hablaban por medio de él. Pero eso usted lo sabe mejor que yo.

-Lo que todavía no sé es quién estuvo detrás del crimen. Si usted está segura que no fue Zorrilla, ¿quién pudo ser?

-Yo no estoy segura de nada, nadie puede estar seguro de nada en este país. ¿Usted cree que el pobre de Aburto fue realmente el asesino de Colosio? Una cosa es el gatillero y otra el asesino.

-Pero usted debe haber escuchado de labios de Manuel algunos nombres.

-Me pide nombres, como si el propio Manuel hubiera conocido a sus futuros asesinos, como si me lo hubiera dicho. ¿Usted cree que a un periodista como Manuel Buendía lo mató alguien con nombre y apellido? Había demasiados intereses involucrados en ese crimen como para señalar con el dedo a una persona. Fue todo un sistema de corrupción e impunidad, en el que se ha sustentado la política mexicana desde hace décadas. Si algo criticó Manuel insistentemente fue la corrupción en las altas esferas del gobierno. A él se debe la idea de que es la corrupción lo que hace funcionar al sistema político mexicano, su principal motor, su columna vertebral desde Carranza y Obregón hasta hoy en día. Todo presidente promete acabar con la corrupción y la impunidad, aunque secretamente sabe que la institución gubernamental y la política en general sólo es posible gracias a ellas. Creo que la pregunta que usted debía hacerse es “¿a quién favoreció el asesinato de Buendía?” Y entonces verá que fueron muchos los sectores o los grupos de fuerza en el país los que vieron con beneplácito y satisfacción el crimen. Incluso, los que pudieron haberlo cometido. 
-Pero esos sectores o grupos de fuerza están constituidos por personas de carne y hueso. Y son ellos los que dan las órdenes. Por eso me interesan los nombres.

-Si es eso lo que le interesa, averígüelo usted mismo. Para eso es periodista. El asesinato de Manuel tiene muchas caras. Creo que todo aquel que esté en contra de la libertad de opinión, que esté a favor de alguna forma de censura, porque tiene algo que esconder ante la ley, es también, de alguna manera, responsable del crimen. Después del asesinato de Manuel, han seguido matando periodistas en todo el país y ya nadie se inmuta. La noticia dura unos cuantos días y luego desaparece de los periódicos y de los noticieros. Parece como si nos hubiéramos terminado acostumbrando, como si el asesinato formara una parte necesaria y habitual de nuestra vida política. Y lo que nos ha hecho acostumbrarnos a todo eso es la absoluta impunidad en la que siguen quedando esos crímenes, no sólo de periodistas, sino de políticos, empresarios o simples mujeres que salen una tarde de su trabajo y días después aparecen violadas y asesinadas en un andurrial. Piénselo, ya no se trata sólo de Manuel Buendía. Es el crimen organizado como una forma de vivir de nuestra sociedad, de todos nosotros.

Vi cómo se ponía de pie y me acompañaba hasta la puerta. Sus pies parecían no rozar la madera del piso, como si flotara. Sentí cómo cerraba la puerta con doble cerrojo a mi espalda. Sentí, también, que era una manera de decirme que no volviera, que no se me ocurriera volver a importunarla con mis preguntas estúpidas. En la puerta, antes de que la cerrara a mi espalda, me dijo, con la misma voz monocorde de toda la tarde, que quería estar sola, que quería guardar la memoria de Manuel sólo para ella, que sus recuerdos eran una manera de seguir conversando con él y que en esa conversación nadie más debía intervenir, que quería permanecer con él sin que la perturbaran. Que yo, y la gente como yo, debía respetar su silencio, sobre todo el silencio de Manuel, que era también el suyo. 
Salí a la calle. Me extrañó ver tanto bullicio y ajetreo sobre las aceras. Ese era un barrio tranquilo, alejado de las grandes plazas y avenidas y sin bares, restaurantes o cines, que hubieran justificado tanto jolgorio. Pero la gente se había volcado sobre las calles como si se tratara de un día de fiesta, a pesar de que el cielo estaba nublado y amagaba lluvia. Día aciago, pensé. Me abotoné el saco y me levanté el cuello de la gabardina. Miré el reloj: eran las 6:30 de la tarde.

\section{Nota aclaratoria}

Aunque los personajes y la situación que se describe en este relato son absolutamente ficticios, no ocurre lo mismo con lo que se dice en él. Todos los datos contenidos en el texto han sido tomados de diferentes fuentes que detallaré a continuación. Lo que sí me interesa aclarar es que mi contribución a esta historia consiste únicamente en la creación de dos personajes ficticios que conversan entre sí; lo que se dice entre ellos está tomado íntegramente de lo que se ha publicado en libros y revistas de 1984 a la fecha. Las fuentes que dieron lugar a esta historia son:

Manuel Buendía, La CIA en México, 1984, México, Océano.

Manuel Buendía, La ultraderecha en México, 1984, México, Océano.

Rogelio Hernández, Zorrilla: el imperio del crimen, 1989, México, Planeta.

Carlos Moncada, Periodistas asesinados, 1991, México, EDAMEX.

Jorge Fernández Menéndez, Narcotráfico y poder, 1999, México.

Julio Sánchez García, Los presidentes, 1986, México, Grijalbo.

Carlos Monsiváis, Prologo a Fuera de la ley..., 1992, México, Cal y Arena.

Sergio Aguayo Quezada, La charola, 2001, México, Grijalbo. 
ARMANDO PEREIRA

Jesús Blancornelas, Horas extra. Los nuevos tiempos del narcotráfico, 2003, México, Plaza y Janés.

Miriam Laurini y Rolo Diez, Nota Roja 80’s, 1983, México, Diana.

Revista Proceso, México, 1984-1988. 